\title{
Spatial SDR performances across three species of new world monkeys'
}

\section{ROBERT L. GOSSETTE and PHILIP SLONIM, Comparative Animal Behavior Laboratory, Hofstra University, Hempstead, L. I., N. Y. 11550}

To provide further information concerning the sensitivity of SDR methodology to performance differences of closely related species among the New World monkeys, the spatial SDR performances of Owl monkeys were measured and compared to those of Squirrel and Capuchin monkeys previously reported. The error scores of the Owls were more similar to those of Squirrel monkeys, than to the Capuchins, which provides some support for the view that the Squirrel is taxonomically more closely related to the Owl than to the Capuchin.

One of the most promising of methodologies in the calibration of interspecies performance differences in comparative behavioral analysis is successive discrimination reversal (SDR). Summarizing a number of experiments employing Ss from fish, reptiles, birds, and mammals, Bitterman (1965) noted that avian and mammalian performance clearly differed from that of fish, and under some conditions, reptiles as well, in that birds and mammals display a distinct reduction in errors across successive reversals. Fish and reptiles, except on a spatial task, generally fail to display such improvement. More recently, it has been suggested (Gossette, 1966) that an even more refined calibration of SDR performance differences via absolute scores may be feasible among organisms that are relatively homogeneous in morphology and behavior. The relatively crude dichotomous scaling of performance differences across classes proposed by Bitterman may be augmented by a rank order scaling of performance across species within smaller taxonomic units, e.g. class, order, or even family. ${ }^{2}$ Thus, it has been shown that a ranking of SDR performances of various species of birds, drawn from different orders, yields an ordering that parallels their taxonomic ranking, with differences in SDR scores correlated with taxonomic distance (Gossette, 1966; Gossette \& Riddell, 1966).

Preliminary study of Squirrel and Capuchin monkeys has shown a similar correlation among New World monkeys (Gossette \& Inman, 1966). To provide further information about the sensitivity of SDR measurement among New World monkeys, a group of Owl monkeys (Douroucoulis) was tested on a spatial SDR task and their scores compared with those of Squirrels and Capuchins, obtained under essentially the same conditions previously described.

\section{METHOD}

Three adult male Owl monkeys obtained from Florida suppliers served as Ss in this experiment. All Ss had been maintained for about 10 months in the laboratory prior to testing and became well habituated to conditions of laboratory maintenance. While this species is normally nocturnal, the lengthy habituation to the diurnal conditions of the Vivarium had resulted in a clear shift in their activity cycle so that testing could be conducted during the late afternoon. Daily diets consisted of Purina monkey chow and bananas supplemented with vitamins.

The apparatus employed in spatial SDR measurement was the same form board box used with the Squirrel and Capuchin monkeys and is fully described in the report of that data.

Ad lib weights were obtained for each $S$ for a period of 5-6 weeks. Then each $\mathbf{S}$ was placed on a deprivation schedule to reduce its body weight by $10 \%$. During this period each S was

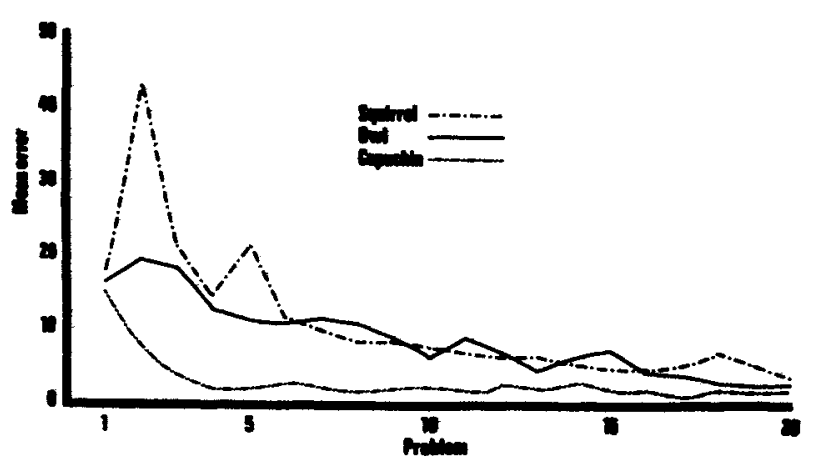

Fig. 1. Mem error per problem scross 19 reversab of a patial hobit for three species of New Wordd monkeys.

habituated to the test chamber, and as it reached its assigned weight reduction level, trained by successive approximations to dislodge stimulus blocks to obtain one eighth of a grape from the underlying food wells. When response to the stimulus blocks was well established, a position habit was established, with reinforcement provided for the response to the nonpreferred position. A criterion procedure was employed, with daily sessions of 20 noncorrection trials, until two or fewer errors were recorded on a given day's session. At that point, the reinforcement contingencies were reversed, and training proceeded as before. In this fashion a total of 19 reversals were obtained.

\section{RESULTS AND DISCUSSION}

Two principal response measures selected for comparison were the total errors and the total correct responses on the first session of each probfem, across all 20 problems. Table 1 presents the means and standard deviations for each measure for the three species. Analysis of both measures by the Kruskal-Wallis test revealed significant differences $(p<.05)$ on

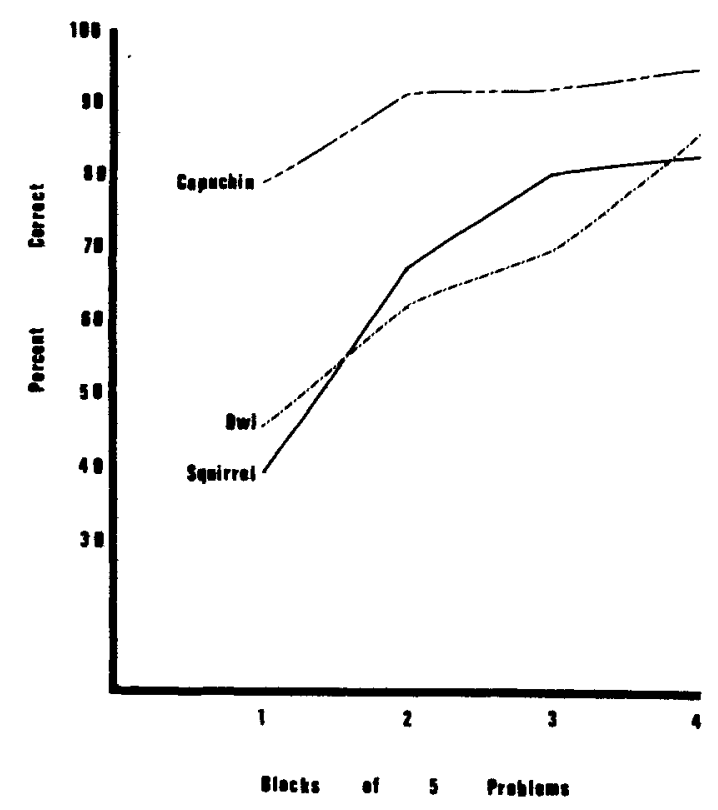

Fig. 2. Pex cent correct on first session of each problem for three species of New World monkeys across 20 problems. 
Table 1

Mean and Range of Total Errors Across 20 Spatial Problems

\begin{tabular}{llll}
\hline & Capuchin & Squirrel & Owl \\
\hline Mean & 54.2 & 208.2 & 170.0 \\
Range & $30-75$ & $150-310$ & $120-235$ \\
\hline
\end{tabular}

both measures. As Figs. 1 and 2 suggest, the Capuchins were appreciably superior to the Squirrel and Owl monkeys in reducing errors across the 20 problems. However, there was considerable overlap by $\mathrm{OWl}$ and Squirrel scores on both measures. Only on the second and third problems, which typically generate the greatest amount of negative transfer with most other vertebrates, was there a prominant difference between performances of Owls and Squirrels. Both groups appeared to be approaching asymptotic performance equal to that of the Capuchin, e.g., one error per problem.

The similarity of Owl and Squirrel SDR performances are of considerable interest in view of their traditionally assigned taxonomic status. Squirrel monkeys (Samiri) are usually grouped with the Capuchins in the subfamily Cebinae, while the Owls are assigned to a presumably phyletically inferior subfamily Aotinae (Simpson, 1962). However, there has been considerable controversy concerning the placement of the Squirrel in Cebinae. Some authors (Hill, 1960) have argued that Samiri are more closely related to Owl monkeys (Aotoes) than to the Capuchin (Cebus) on both morphological and behavioral grounds. To the extent that similarity of patterns of such performances as that measured by SDR are diagnostic of interspecies taxonomic distances 2 the data reported above would provide additional support for this argument.

\section{REFERENCES}

BITTERMAN, M. E. The evolution of intelligence. Scientific American, 1965, 212,92-100.

GOSSETTE, R. L. Comparisons of successive discrimination reversal (SDR) performances across fourteen different avian and mammalian species. American Zoologist, 1966, 6. (Abstract)

GOSSETTE, R. L., GOSSETTE, M., \& RIDDELL, W. Comparisons of successive discrimination reversal performances among closely and remotely related avian species. Animal Behavior, 1966, 14, 560-564.

GOSSETTE, R. L., \& INMAN, N. Comparison of spatial successive discrimination reversal performances of two groups of New World monkeys. Perceptual \& Motor Skills, 1966, 23, 169-170.

HILL, W. C. O. Primates. Vol. IV. Cebidae. Edinburgh: Edinburgh University Press, 1960.

SIMPSON, G. G. Primate taxonomy and recent studies of nonhuman primates. Annals of the New York Academy of Sciences, 1962, 102, 497-514.

\section{NOTES}

1. Supported in part by NIMH Grant No. 14079-01 awarded to first author.

2. Gossette, R. L. Successive discrimination reversal measures and interspecies taxonomic distance. Unpublished manuscript.
Table 3

R/A Comparison with Results of Rumbaugh \& Pournelle (1966)

\begin{tabular}{lcc}
\hline & Rumbaugh \& Pournelle $(\mathrm{N}=7)$ & Present Study $(\mathrm{N}=5)$ \\
\hline Mean & .899 & .894 \\
Standard deviation & .044 & .049 \\
Range & .110 & .131 \\
\hline
\end{tabular}

comparison of the $\mathrm{R} / \mathrm{A}$ ratios for the five animals based on all 100 object pairs shows that the mean value departs significantly from $1.00(t=4.42, \mathrm{df}=4, \mathrm{p}<.01$, on a one-tailed test). In other words there is clear evidence that learning was occurring.

The remarkable similarity between our $R / A$ ratios and those based on Rumbaugh \& Pournelle's (1966) data requires comment. Table 3 compares the mean R/A values for this study and the Rumbaugh and Pournelle study and indicates that the mean, the standard deviation, and the range were very close indeed. On the one hand, this similarity could be interpreted as evidence in favor of the robustness of the R/A ratio and its relative independence of previous learning and any slight differences in procedure. On the other hand, it could be interpreted as evidence that the $R / A$ ratio is somewhat insensitive to genuine differences in learning ability. Since Rumbaugh and Pournelle state that "these particular squirrel monkeys were superior in their DR skills, for they had been selected for use as Ss in the Rumbaugh and Ensminger study by reason of their relatively high-order learning-set performance in earlier experiments," one might have hoped that the R/A ratio for their animals would have differentiated them from the randomly-selected animals used in this study. In this respect there seems to be something to be said in favor from page 221)

of the RI when making comparisons between animals of the same species. The spread of values for RI for the five animals in this study is from 0.528 to 2.529 . By comparison, the R/A values are very closely clustered together-from .814 to .945 in the present study, and from .866 to .976 in the Rumbaugh and Pournelle study. In fact, four values out of the seven are almost the same, i.e., $.866, .866, .867$, and 868 .

The $100 \%$ correspondence between the RI and R/A ranking increases our confidence in the suitability of the RI for use with primates as well as subprimates. It is worth noting that whereas the time taken to gather the data for RI calculations ranged from 8 days to 34 days, it took from 33 days to 57 days to collect the data to compute the $R / A$. A further limitation of R/A is the stipulation that it should only be used when the $A \%$ s are approximately equal; with subprimates this is highly unlikely, although the present experiment shows that with primates of the same species, the chances are better. This requirement of equivalent $\mathrm{A} \% \mathrm{~s}$ would, however, make it difficult to use the R/A for making ontogenetic comparisons with primates within the same species. By comparison the RI has been shown to reflect ontogenetic differences (Jeeves, 1967).

JEEVES, M. A. The reversal index and ageing. Psychonomic Science, 1967, 9, 371-372.

RAJALAKSHMI, R., \& JEEVES, M. A. The relative difficulty of reversal learning (reversal index) as a basis of behavioural comparisons. Animal Behaviour, 1965, 13, 203-211.

RUMBAUGH, D. M., \& JEEVES, M. A. A comparison of two discrimination-reversal indices intended for use with diverse groups of organisms. Psy chonomic Science, 1966, 6, 1-2.

RUMBAUGH, D. M., \& POURNELLE, M. B. Discrimination-reversal skills of primates: The reversal/acquisition ratio as a function of phyletic standing. Psy chonomic Science, 1966, 4, 45-46. 